The research is devoted to the study of the features of digital socialization understood as mediated by all available digital technology process of mastering and appropriating a social experience, acquired in the online contexts, the reproduction of this experience in mixed offline/online reality and shaping digital personality as part of a real personality.

The sample included 1553 adolescents 12-17 years old and 1219 parents from 8 Federal districts of the Russian Federation. In accordance with the indicators of digital socialization, the questionnaires included blocks of questions devoted to the digital world image, perception and exchange of information, communication with the living and non-living elements of the online space, online consumption, as well as social-cultural, psychological and technical aspects of $\mathrm{e}$ devices use.

The paper presents some of the findings of the study. Among adolescents there is a mass and earlier mastering of hi-tech arsenal of new cultural means - the personalized mobile e-devices. Overtaking parental user activity, the duration of the child's online presence increases.
Adolescents master digital space actively, independently and spontaneously, especially new online platforms, and use it as a communication platform and a source of developing, educational and entertainment content. For adolescents, social networks have become an important platform for selfpresentation, mastering various social roles, experimenting with identity and selfrealization.

\section{Online habitats}

adolscents 14-17 years old - parents $827^{82} 72$
40
40
40

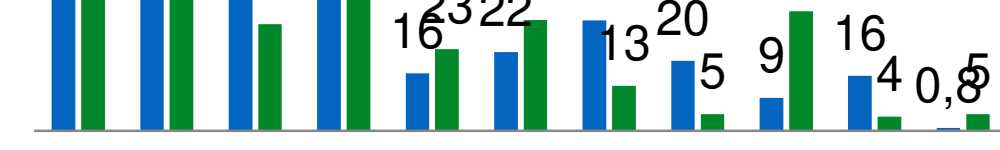

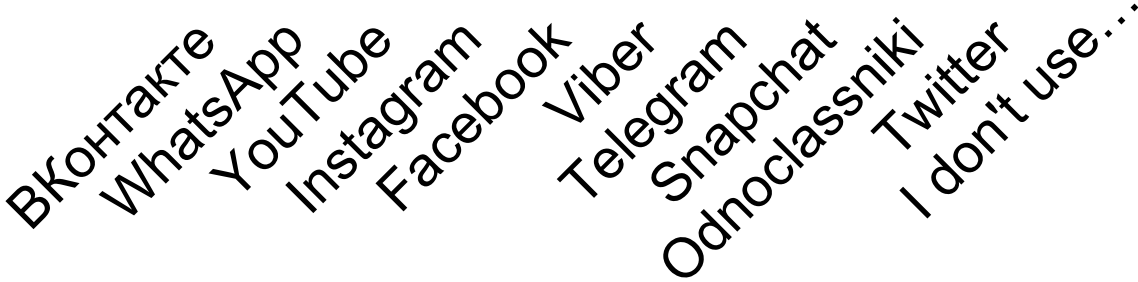

Compared to their parents, adolescents are actively increasing their social capital through online contacts, including weak connections of subscribers and «unfamiliar friends».

\begin{tabular}{|c|c|c|c|c|c|}
\hline \multirow{2}{*}{$\begin{array}{c}\text { Internet use intensity of } \\
\text { adolescents and parents in } \\
\mathbf{2 0 1 3 / 2 0 1 9}\end{array}$} & \multicolumn{3}{|c|}{ ADOLSCENTS } & \multicolumn{2}{c|}{ PARENTS } \\
\cline { 2 - 4 } & $\mathbf{2 0 1 3}$ & \multicolumn{2}{|c|}{$\mathbf{2 0 1 9}$} & \multirow{2}{*}{$\mathbf{2 0 1 3}$} & $\mathbf{2 0 1 9}$ \\
\cline { 2 - 5 } & $\begin{array}{c}12-17 \\
\text { years old }\end{array}$ & $\begin{array}{c}12-13 \\
\text { years old }\end{array}$ & $\begin{array}{c}14-17 \\
\text { years old }\end{array}$ & & \\
\hline Low (average 1 hour) & $9 \%$ & $20 \%$ & $9 \%$ & $31 \%$ & $35 \%$ \\
\hline Average (average 3 hours) & $71 \%$ & $51 \%$ & $40 \%$ & $61 \%$ & $43 \%$ \\
\hline High (average 6 hours) & $13 \%$ & $21 \%$ & $28 \%$ & $5 \%$ & $14 \%$ \\
\hline Hyper-connectivity (average 9 h) & $7 \%$ & $8 \%$ & $23 \%$ & $3 \%$ & $8 \%$ \\
\hline
\end{tabular}

This work is supported by the Russian Science Foundation, project № 18-18-00365 «Digital socialization in cultural-historical perspective: intragenerational and intergenerational analysis»

Thus, online chronotopes, as spatialtemporal configuration of Internet use, differ between adolescents and parents.

Online immersion leads to encounter with new difficult life situations - online-risks. Among online risks, communication risks have become the most common. In second place - content. Every third adolescent was faced with the technical risks, every fifth senior adolescent - with consumer risks. A fifth of adolescents have patterns of Internet addiction. Overall, the older the adolescent, the more he faces online risks

However, parents are often not sufficiently aware of the experience of children facing online risks and do not have the appropriate strategies to provide the necessary support. For example, parents overlook the experience of adolescents in dealing with communication and content risks and overrated the impact with consumer risks.

\section{Facing different types of} risks

- adolscents 12-13 years old

adolscents $14-17$ years old

- parents assessment

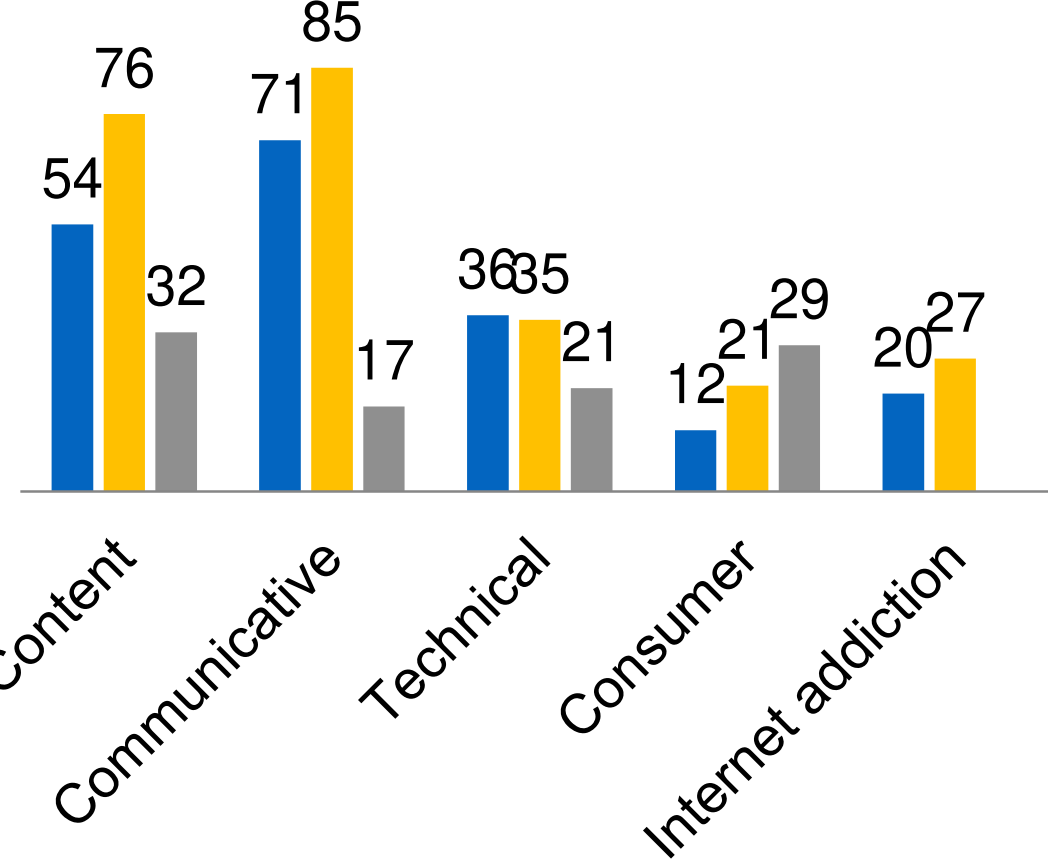

The main support for the adolescent when they faced with online risks is provided by their friends. They turn to parents quite rarely (less than a third). Every sixth, in principle, keeps in secret what happened, staying without any support alone with the problem. Virtually no one is willing to share about what happened with specialists and teachers.

The digital gap between generations of children and parents reduces the universality of the adult figure and its role in child-parent relations.

Nevertheless, parents are trying to become more involved in the digital world of the child. Most parents believe they use strategies of active mediation for the Internet using and safety. Two thirds of parents "friend" their children on social media to monitor their online activity. Every second parent thinks that he or she uses limiting mediation - the rules, especially in sharing personal data in social networks. But children consider their parents to use any of mediation strategies much more rarely than parents evaluate themselves.

Over the past five years the digita competence of children and parents increases (from $31 \%$ of possible $100 \%$ to $41 \%$ in parents and from $35 \%$ to $57 \%$ in adolescents), but if parents have high level of knowledge with a lack of skills and responsibility, then adolescents, on the contrary, have higher skills and responsibility, but knowledge and motivation "lag behind" skills.

Thus, the first results show that digital socialization is a complex and heterogeneous process in terms of intra- and intergenerational analysis and requiring further research. 